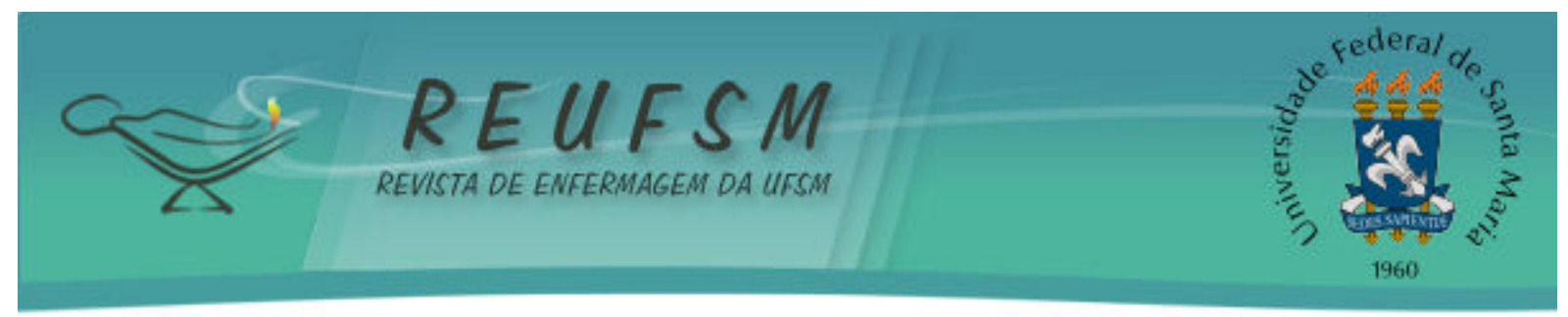

ARTIGO ORIGINAL

\title{
PERCEPÇÃO DOS ENFERMEIROS DAS UNIDADES DE MATERNIDADE E PEDIATRIA ACERCA DO CUIDADO PATERNO
}

\section{PERCEPTION OF NURSES OF MATERNITY AND PEDIATRIC UNITS ABOUT PATERNAL CARE PERCEPCIÓN DE ENFERMEROS DE UNIDADES DE MATERNIDAD Y PEDIATRÍA SOBRE ATENCIÓN PATERNA}

Doi: 10.5902/2179769213589

Bruna Silveira de Almeida ${ }^{1}$ Bárbara Tarouco da Silva² Juliane Portella Ribeiro ${ }^{3}$ Adriane Maria Netto de Oliveira ${ }^{4}$

RESUMO: Objetivo: conhecer a percepção dos enfermeiros das unidades de maternidade e pediatria em relação ao cuidado paterno na família contemporânea. Método: estudo exploratório com abordagem qualitativa. Os participantes foram enfermeiros atuantes nas unidades de maternidade e pediatria de um hospital universitário localizado no extremo sul do Rio Grande do Sul. Para a produção dos dados realizaram-se entrevistas semiestruturadas. Os dados foram submetidos à técnica de análise textual discursiva. Resultados: emergiram duas categorias: "Cuidado paterno na família contemporânea" e "Assistência de enfermagem: fatores que influenciam a participação do homem no cuidado dos filhos". Conclusões: os entrevistados evidenciaram o distanciamento entre o preconizado pelas políticas públicas e literatura científica com a realidade nas instituições de saúde.

Descritores: Paternidade; enfermagem; enfermagem familiar; relações pai-filho

ABSTRACT: Objective: to raise awareness about the perception of nurses in maternity and pediatric units in relation to paternal care in the contemporary family. Method: exploratory study with a qualitative approach. The participants were nurses working in maternity and pediatric units of a university hospital located in southern Rio Grande do Sul. Semi-structured interviews were carried out for data collection and data were analyzed through discursive text analysis. Results: two categories emerged from the analysis: "paternal care in the contemporary family" and "Nursing care: factors that influence the participation of men in childcare". Conclusions: respondents highlighted the gap between what is recommended by public policies and by scientific literature and the reality in health institutions.

Descriptors: Paternity; nursing; family nursing; father-child relations.

\footnotetext{
1 Enfermeira. Graduada pela Escola de Enfermagem da Universidade Federal do Rio Grande. Rio Grande, RS, Brasil. bruna_s_almeida@hotmail.com

2 Enfermeira. Doutora em enfermagem. Professora da Escola de Enfermagem da Universidade Federal do Rio Grande. Rio Grande. Rio Grande do Sul. Brasil. barbarataroucos@gmail.com

3 Enfermeira. Psicóloga. Especialista em Saúde Mental no Contexto Multidisciplinar. Doutoranda em Enfermagem pelo PPGEnf/FURG. Rio Grande. Rio Grande do Sul. Brasil. ju_ribeiro1985@hotmail.com

${ }^{4}$ Enfermeira.Doutora em Enfermagem. Docente do Curso de Graduação em Enfermagem, do Curso de PósGraduação em Enfermagem, do Curso de Pós-Graduação em Ciências da Faculdade de Medicina, da Especialização Abordagem Multidisciplinar em Dependência Química do Instituto de Ciências Biológicas e da Residência Multiprofissional em Saúde da Família, da Universidade Federal do Rio Grande. Rio Grande do Sul. Brasil. adrianenet@vetorial.net
} 


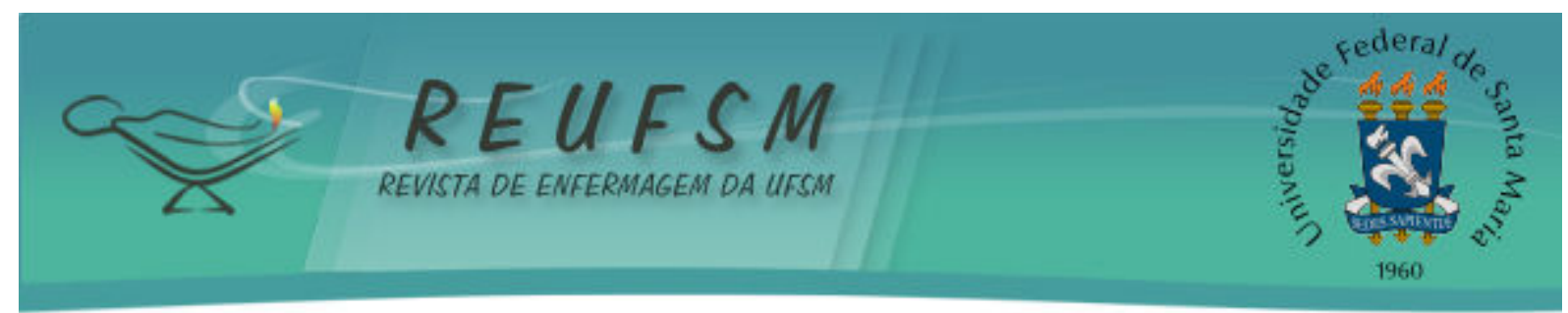

RESUMEN: Objetivo: conocer la percepción de los enfermeros de maternidad y pediatría en relación al cuidado paterno en la familia contemporánea. Método: estudio exploratorio cualitativo. Las participantes fueron enfermeras que trabajan en las unidades de maternidad y pediatría de un hospital universitario localizado en el sur de Rio Grande do Sul (Brasil). Para la recolección de datos se llevaron a cabo entrevistas semiestructuradas. Los datos fueron sometidos a la técnica de análisis textual discursivo. Resultados: de los análisis emergen dos categorías: "el cuidado paterno en la familia contemporánea" y "Atención de enfermería: factores que influyen en la participación del hombre en el cuidado de niños". Conclusiones: los entrevistados destacaron la brecha entre las recomendaciones de las políticas públicas y la literatura científica con la realidad de las instituciones de salud.

Descriptores: Paternidad; enfermería; enfermería de la familia; relaciones padre-hijo.

\section{INTRODUÇÃO}

O envolvimento paterno nas ações de cuidado é um dos recursos mais importantes e, no entanto, pouco utilizado na promoção da saúde e no desenvolvimento das crianças e dos adolescentes. Na assistência de enfermagem às famílias, observa-se que o foco dos cuidados de saúde ainda está voltado majoritariamente para a mãe e a criança. 0 pai permanece como uma figura que se destaca pouco, embora tenha um papel fundamental no projeto de vida familiar. ${ }^{1}$ Pesquisa aponta que o pai é colocado à margem do processo reprodutivo, enfrentando barreiras de conhecimento, sociais e psicológicas para participar dos momentos de gestação, parto e puerpério. ${ }^{2}$ Tal fato, evidência que os serviços de saúde não estão preparados para identificar e responder às demandas dos pais que procuram exercer a paternidade.

Os pais ainda esbarram em inúmeras dificuldades para acessar os serviços de saúde, desde barreiras institucionais, como a inexistência de atividades direcionadas para eles, até questões culturais, como a reprodução ser considerada exclusivamente feminina. Além disso, a maioria das empresas dificultam a liberação dos homens para acompanhar suas parceiras nas consultas de pré-natal e de puericultura. ${ }^{3}$

Nesta perspectiva, pesquisadores trabalham para desmitificar a figura paterna na sua relação de cuidado com o(s) filho(s), expondo a ideia de que o homem, cada vez mais, procura compartilhar com a companheira as responsabilidades familiares, apoiando-a emocionalmente não só durante o período gravídico puerperal, mas também cuidando do filho após o nascimento. ${ }^{1}$

Ademais, pesquisa ${ }^{4}$ acerca da paternidade realizada na última década ressalta a importância do envolvimento e participação do pai no cuidado dos filhos. Conforme constatou o estudo ${ }^{5}$ realizado com objetivo de conhecer a ligação emocional do pai com o bebê no final da gravidez, aumentando o seu envolvimento durante a gravidez e no parto, é possível melhorar a ligação emocional entre este e o bebê com repercussões positivas para ambos e para o casal. No entanto, é preciso que os profissionais de saúde promovam a participação do homem nas consultas de pré-natal, preparativos do parto e parto e consultas de puerpério.

Tendo em vista os efeitos que o envolvimento paterno pode proporcionar à criança, à mãe e ao desenvolvimento do próprio homem, a Enfermagem deve potencializar a participação do pai na gestação, parto e cuidado ao filho, assim, contribuindo para interações positivas na dinâmica familiar. Para integrar o pai às práticas de cuidado, é necessário que os profissionais estejam capacitados para atuar com criatividade e humanização, compreendendo que estes são eventos que integram a vivência de homens e mulheres. ${ }^{3}$ 


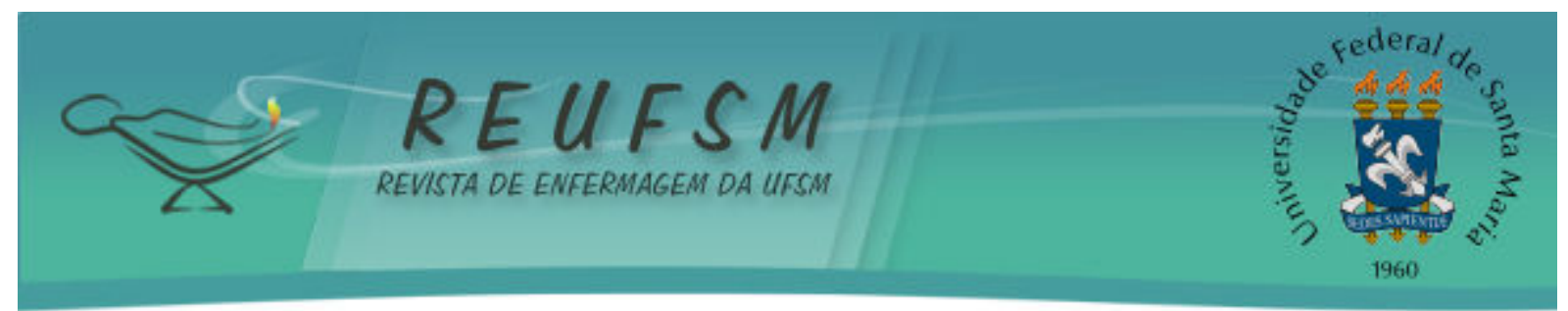

A assistência de enfermagem necessita romper com o paradigma social, o qual concebe a mãe como única cuidadora, e incorporar a nova realidade, em que o pai paulatinamente insere-se no cuidado aos filhos. Nessa perspectiva, este estudo justifica-se pela possibilidade de contribuir na discussão sobre a participação do pai no cuidado dos filhos. Teve como questão norteadora: qual a percepção dos enfermeiros acerca do cuidado paterno na família contemporânea? 0 objetivo foi conhecer a percepção dos enfermeiros das unidades de maternidade e pediatria em relação ao cuidado paterno na família contemporânea.

\section{MÉTODO}

Trata-se de um estudo exploratório com abordagem qualitativa, derivado do projeto "Práticas de cuidado de enfermagem aos homens que vivenciam a paternidade" aprovado pelo Comitê de Ética e Pesquisa com Seres Humanos da Universidade Federal do Rio Grande (CEPAS/FURG), sob parecer número 60/2012. O cenário de estudo foram as unidades de Pediatria e Maternidade de um hospital universitário do interior do Rio Grande do Sul.

Os participantes foram os 15 enfermeiros que atuam nas unidades referidas anteriormente, respeitando o critério de inclusão: ser enfermeiro assistencial atuante em unidades hospitalares maternidade e pediatria e o critério de exclusão: não atuar nas referidas unidades. Para garantir os princípios éticos de sigilo e anonimato, estes foram identificados com a letra "E", seguidas do número indicando a ordem de realização das entrevistas.

Para a produção dos dados realizaram-se entrevistas semiestruturadas, gravadas em aparelho digital. A coleta dos dados foi realizada no período de setembro a outubro de 2013, em local e horário previamente agendado de acordo com a disponibilidade dos participantes. Os dados provenientes das entrevistas foram transcritos na íntegra, lidos e analisados por meio da técnica da análise textual discursiva, ${ }^{6}$ assim, emergiram as categorias: "Cuidado paterno na família contemporânea" e "Assistência de enfermagem: fatores que influenciam a participação do homem no cuidado dos filhos".

\section{RESULTADOS E DISCUSSÃO}

\section{Cuidado paterno na família contemporânea}

Nesta categoria emergiram três eventos em destaque: a forma de participação do pai no cuidado dos filhos; os motivos que levam o pai a participar do cuidado; e por último, os fatores que levam a não participação do cuidado.

O primeiro evento, a forma de participação do pai no cuidado dos filhos referese ao compartilhamento das atividades entre o casal. Na visão dos participantes do estudo, o envolvimento do pai começa desde o pré-natal, na participação durante as consultas, quando o homem demonstra preocupação com o desenvolvimento da criança e adota alguns cuidados em relação à saúde da esposa. Esse envolvimento deve se estender durante todo período de gestação, parto e pós-parto.

A participação do homem durante o processo gestacional é expressa por atitudes, comportamentos e sentimentos em relação à mulher e à criança. Durante o parto, o homem passa segurança para a mulher de forma que esta se sente protegida em saber que está com alguém do seu núcleo familiar. Já, no período pós-parto o homem atua como suporte emocional e participa dos primeiros momentos junto à nova família, auxiliando a mulher nas atividades que ainda são novas para ambos, como amamentação e cuidados com o bebê. 


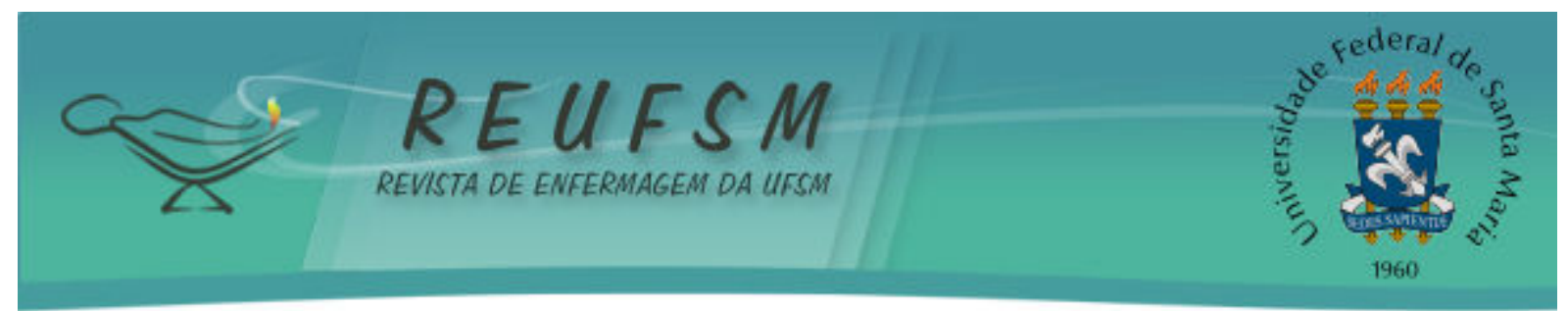

Esse resultado assemelha-se aos achados do estudo realizado no Hospital de Clínicas em Porto Alegre-RS, com objetivo de conhecer a participação do pai como acompanhante da mulher durante o parto, apontando que alguns pais consideram sua presença importante em todo processo de parturição, por poderem oferecer apoio emocional à mulher, dando-lhe segurança por meio de palavras, gestos de carinho e conforto. ${ }^{7}$ Além disso, pesquisadores constataram que mulheres em trabalho de parto ao ficarem sozinhas sentem medo e insegurança, solicitando a presença de um acompanhante para que se sintam mais calmas e seguras no momento de parturição. ${ }^{8}$

Alguns autores destacam o surgimento do conceito de um novo pai, preocupado não apenas em prover as necessidades básicas do filho, mas também em estar presente, acompanhando o seu desenvolvimento e provendo as necessidades de afeto e amor. ${ }^{9}$ Os entrevistados percebem que o homem vem assumindo algumas tarefas de cuidado, especialmente atividades de higiene, alimentação, lazer e educação dos filhos. Contudo, os Enfermeiros destacaram que a participação do homem existe, porém eles atuam como coadjuvantes, se envolvendo, especialmente nas atividades escolares e de lazer, pouco participativo nas demais atividades de cuidado.

Estão participando mais do cuidado dos filhos e das tarefas de casa, ajudando, porque uma coisa é assumir como a mulher assume e outra coisa é ajudar quando eles podem. Eles ajudam [...] colaboram, mas não acham que o compromisso é deles. (E7)

$\mathrm{Na}$ percepção dos Enfermeiros, quando o homem está presente no serviço de saúde devido a doença do filho, ele atua principalmente como companhia e suporte emocional a esposa, sendo que a responsabilidade dos cuidados ainda recai sobre a mulher. Destacou-se, ainda, que a participação do homem não se detém apenas no cuidado dos filhos, mas está voltada também para o cuidado da esposa.

O pai é mais da história do tudo eles querem saber, querem estar a par das coisas, mas na hora da prática mesmo do fazer, fica sempre para mãe [...] Dão suporte emocional, mas também não é muito porque eles tão mais ansiosos acho do que as mães [...]. (E3)

Participam tanto na higiene quanto no cuidado com a mãe, eles são bem participativos, desde quando interna [a gestante], nas consultas [pré-natal], no trabalho de parto são bem participativos, eles ajudam muito no banho, na higiene, na amamentação [...] são bem comprometidos. (E10)

Em conformidade com os resultados obtidos, estudo realizado com o objetivo de analisar a concepção dos profissionais de saúde sobre a participação do homem nos diferentes aspectos do processo reprodutivo, identificou que os homens estão presentes no serviço de saúde, compartilhando com a esposa os vários momentos vivenciados durante o período da internação. Suscitando dos profissionais a ampliação de seus conceitos e práticas, revisando a forma como o homem é acolhido no sistema, estabelecendo vinculo e a responsabilização criada entre o profissional e o homem. ${ }^{10}$

O segundo evento aponta os motivos que levam o pai a participar do cuidado. Dentre eles destacam-se as mudanças sociais, culturais e econômicas ocorridas ao longo do tempo, as quais impuseram a transição do modelo de paternidade patriarcal, ancorado na figura autoritária e do pai provedor para o modelo de paternidade no qual o pai é visto 


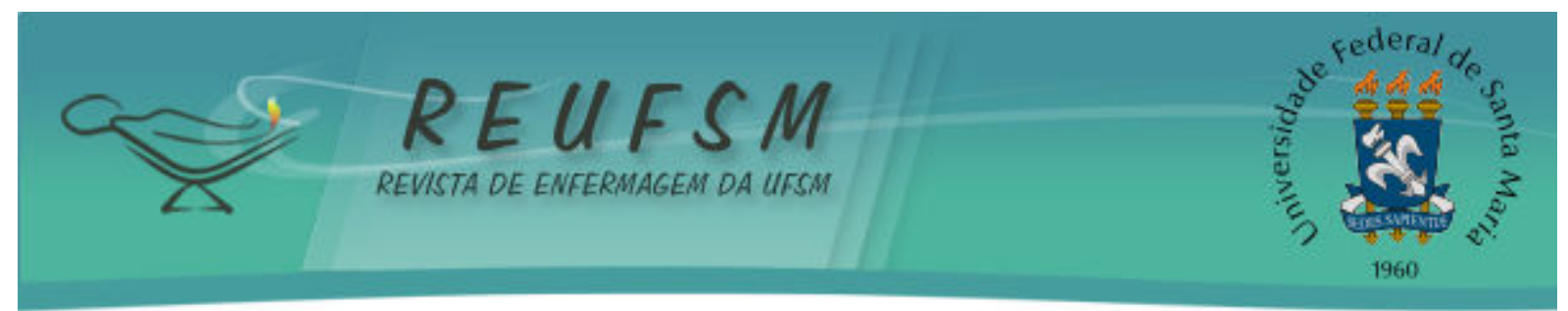

como um sujeito participante da criação dos filhos, preocupado em demonstrar afeto nas relações estabelecidas dentro da família. Nos depoimentos ficou evidente que a visão do homem como provedor, responsável unicamente pelo sustento financeiro da família, vem sofrendo um processo de transição.

Hoje eles estão mais presentes, se envolvem mais, ficam com a criança, há um tempo a gente não via [isso]. Alguns participam no cuidado sim, outros não, estão só de visita, até ficam, mas os cuidados [que realizam] são poucos. (E9)

Acho que mudou bastante, acho que teve uma época que o homem era o provedor da casa e não tomava liderança a questões relativas aos filhos [...] hoje a história já mudou bastante porque a mulher sai para trabalhar, a mulher tem uma outra postura e o homem acaba interagindo mais em outras questões que antes ficava a parte eu acho que ele se envolve bem mais hoje. (E4)

Estudo realizado com pais, com objetivo de analisar os significados atribuídos à paternidade, em João Pessoa-PB, mostrou que predomina no discurso masculino a visão de responsabilidade paterna associada ao bem-estar dos filhos, no sentido de thes garantir a subsistência e a proteção. Os homens relataram a importância de estarem presentes na vida dos filhos. ${ }^{11}$ No entanto, alguns autores afirmam que apesar de os pais terem competência para atuar no cuidado, a maior parte da responsabilidade com as tarefas básicas é assumida pela mãe. ${ }^{12}$

Outro motivo que favorece a participação do pai no cuidado é o conhecimento dos eventos ocorridos durante a gestação, parto e pós-parto que podem influenciar o modo como o homem vivencia a chegada dos filhos, contribuindo na tomada de decisões, iniciativas ao cuidado com a criança e estabelecimento precoce do vínculo. Esse aspecto pode influenciar positivamente a participação do homem na criação dos filhos, preparando-o para determinadas situações, como as mudanças e imprevistos ocorridos nesse período.

Nesse sentido, o Enfermeiro pode atuar incentivando a participação do homem no cuidado, o que propicia o estabelecimento de vínculo precoce e contribui para o desenvolvimento da criança.

Os cuidados que tem que ser feitos com a criança, por exemplo, se vai ter alta e a criança vai com uma sonda a gente orienta o pai e orienta a mãe, então ajuda os dois a participarem desses cuidados, alimentação, banho, todos esses cuidados [...] a gente procura orientar para que ele se sinta capaz. (E11)

Autores, também, destacam como fatores favoráveis a participação do pai na família, os novos papéis sociais que o casal vem assumindo, a disponibilidade de tempo e interesse dos pais, o desenvolvimento do processo educativo na atenção básica e o estímulo dos profissionais, em especial os enfermeiros para a participação e inclusão do pai desde o pré-natal. ${ }^{4}$

Com a inserção da mulher no mercado de trabalho, o homem passa a ter maior oportunidade de participação nas questões familiares, dividindo tarefas que eram exclusivas das mulheres. Assim, na família contemporânea, o casal passa a desempenhar atividades semelhantes, dividindo o sustento financeiro e as atividades referentes à criação e educação dos filhos. 


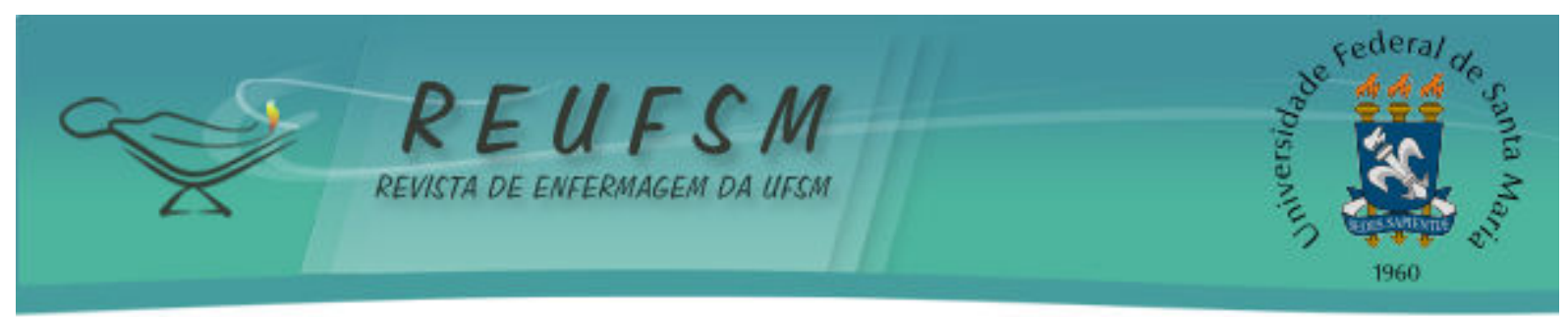

O fato da mulher ter ficado mais independente, indo em busca de outras coisas, de trabalho, de estudar, dessa necessidade de crescimento que a mulher tem hoje e que força de alguma maneira a participação do homem na família, com os filhos, inclusive com o cuidado da casa. Eu acho que o que favoreceu esse envolvimento foi justamente a saída da mulher para buscar novas conquistas. (E15)

Estudo realizado na Bahia ${ }^{13}$ com objetivo de analisar a participação de homens no pré-natal e parto de suas parceiras apontou que os pais vêm assumindo outras tarefas no âmbito familiar, rompendo com a visão de pai somente provedor. Os autores destacaram que fatores socioeconômicos e a inserção da mulher no mercado de trabalho vêm contribuindo com a aproximação paterna aos aspectos afetivos da família.

Os Enfermeiros destacaram que as mudanças sociais, culturais e econômicas influenciam os papéis do homem e da mulher na família. Três aspectos importantes que influenciam o modo de participação paterna foram apontados pelos participantes: as características individuais do homem, do contexto no qual está inserido e o modelo de paternidade vivenciado na família de origem.

Consideram-se como características individuais do pai o seu conhecimento, suas experiências pessoais e a capacidade de envolver-se na dinâmica familiar. Em relação ao contexto destacam-se as interações vivenciadas pelo homem na família de origem e a situação financeira. Além disso, as experiências vividas pelos pais e os valores transmitidos por seus genitores influenciam na criação de seus filhos. Alguns homens, criados no modelo de paternidade patriarcal, procuram reformular seu papel na família ao invés de reproduzir a experiência vivenciada ao se tornar pai.

O meio no qual o homem está inserido influencia [...] 0 modo como ele foi criado, a situação econômica, a cultura, sua educação, isso tudo são fatores que favorecem a participação do homem nas questões familiares. (E12)

No terceiro evento, os motivos que levam a não participação paterna, os participantes apontam a indisponibilidade de horário em função do trabalho e a inexperiência de alguns pais em lidar com a criança. Os pais apesar de sentirem a necessidade de estarem presentes, acabam tendo algumas limitações devido à jornada de trabalho, a falta de flexibilidade no horário o que dificulta a conciliação da vida profissional e familiar e, muitas vezes, inviabiliza a presença durante as consultas pré-natal e acompanhamento durante a internação hospitalar, dificultando assim sua participação.

$\mathrm{Na}$ visão dos Enfermeiros, os homens demonstram interesse em participar de todos os aspectos que dizem respeito aos filhos. No entanto, como não conseguem conciliar o horário de trabalho e não possuem liberação da atividade laboral, utilizam algumas estratégias para estar presente nos serviços de saúde. Alguns homens fazem contato telefônico para receber notícias do filho, outros estão presentes em horários alternados ou finais de semana.

Alguns vêm em horário de visita, outros vêm aos finais de semana, alguns ligam pra saber por telefone o horário de visita porque não coincide o horário com o horário que ele poderia vir. (E11)

Em consonância com os resultados obtidos, um estudo visando conhecer os aspectos limitantes no processo de paternidade, aponta alguns fatores que dificultam a participação paterna como: a questão cultural; a não liberação do homem do trabalho; a 


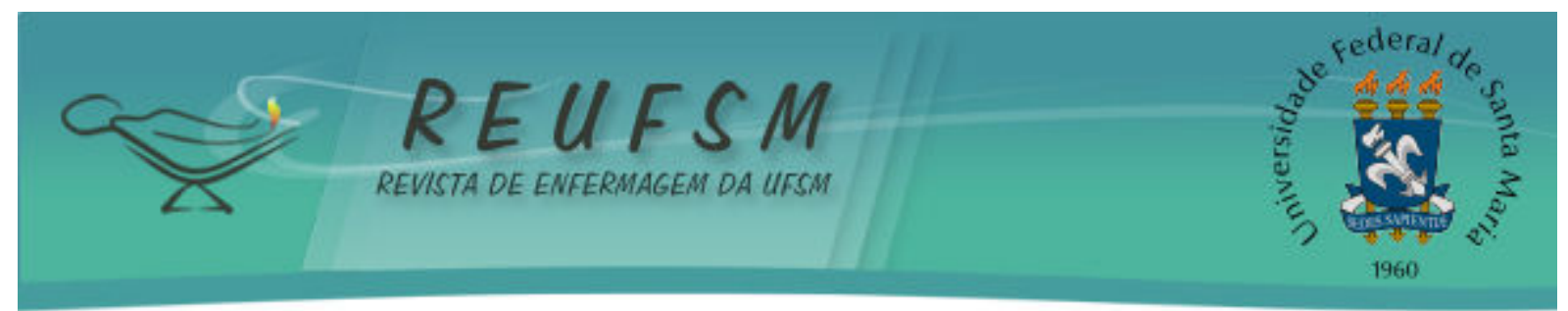

incompatibilidade de conciliar os horários do trabalho e o das consultas; e o despreparo dos profissionais para a inclusão do pai. ${ }^{4}$

O segundo motivo em destaque para a não participação foi a inexperiência do pai no que se refere ao cuidado. Os pais que tiveram alguma experiência mostram-se mais seguros no cuidado da criança, sabendo como agir nas diversas situações vivenciadas. Já aqueles que não tiveram nenhuma vivência, demonstram-se inseguros e receosos em participar do cuidado, solicitando o apoio da esposa e do profissional enfermeiro para lidar com a criança.

Eu percebo assim, os que são pais de primeira viagem tem mais receio, os que já têm filhos em casa já tem mais iniciativa se o bebê está chorando e a mãe está descansando [ele atende a criança]. Já vi pai trocando a fralda, mas tu vê que não é pai de primeira viagem, tem outros filhos. Eles trocam fralda, enrolam o umbiguinho. (E12)

De acordo com os resultados obtidos, estudo realizado com a finalidade de analisar os sentimentos dos pais diante do nascimento dos filhos, foi constatado que o pai vivencia momentos de inquietação, medo, insegurança, nervosismo e preocupação, cabendo aos profissionais envolvidos, em destaque o enfermeiro, interagir com o pai, fornecendo apoio e confiança para participar desse momento tão importante. ${ }^{1}$

Uma das questões que se destacou foram as mudanças no relacionamento do casal durante a gestação e o nascimento dos filhos. As mudanças ocorridas com o corpo e comportamento da mulher no período gestacional e a atenção voltada quase que somente a ela e ao bebê, faz com que o homem sinta-se excluído do processo gestacional, esse distanciamento implica em dificuldades para entender os eventos ocorridos nesse período, impossibilitando-o de desenvolver seu papel como pai participativo.

[...] o relacionamento da mulher com ele, muda, eles ficam mais preocupados, ansiosos, pois não conseguem entender as mudanças que ocorrem na gestação. (E10)

Em consonância com os resultados obtidos, estudo realizado com casais em uma maternidade no Rio de janeiro, com objetivo de descrever as vivências destacadas pelos pais diante da gravidez, apontou que as mudanças ocorridas no período gestacional não se tratam apenas em relação ao corpo da mulher, mas também, nas suas relações e em seus sentimentos. Essas mudanças vêm acompanhadas de dores, náuseas, desconforto e consequentemente oscilações de humor, podendo assim dificultar o relacionamento do casal. $^{14}$

\section{Assistência de enfermagem: fatores que influenciam a participação do homem no cuidado dos filhos}

Nesta categoria destaca-se como evento significativo a preparação dos profissionais para incluir o pai na assistência prestada à família. Os entrevistados destacaram a importância da presença do pai e referiram o incentivo a sua participação. Também, apontaram que a participação deverá se dar desde o início da gestação, durante as consultas de pré-natal, recebendo orientações e sendo preparado para a chegada do filho. Esses aspectos favorecem o fortalecimento dos laços familiares e o vínculo pai e filho desde o período gestacional. 


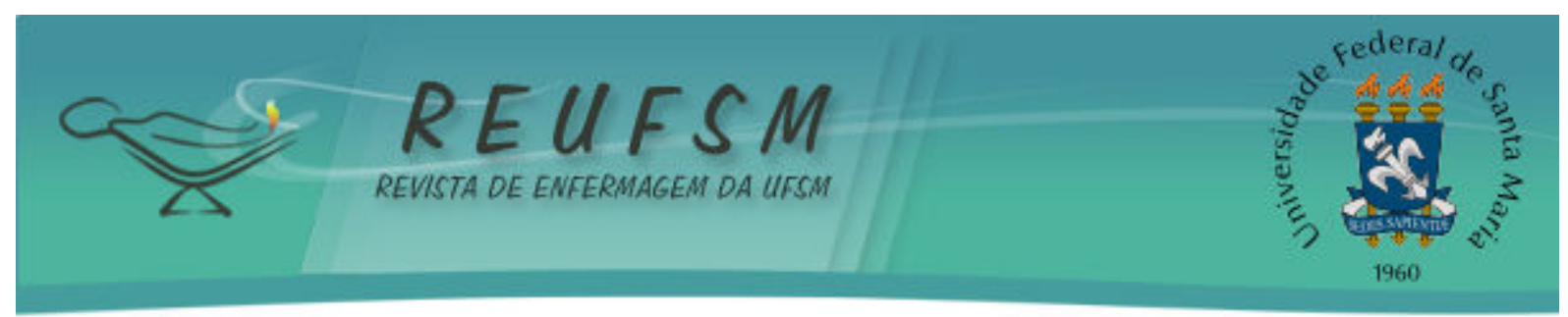

A questão do vínculo com a criança é imprescindível. [o pai] tem que cuidar, tem que ajudar [...] Aí vai de o profissional chamar, se tu deixar só pelo pai, dificilmente eles vão ter uma atitude de tomar à frente. (E4)

As interações que os profissionais de saúde estabelecem com o pai são determinantes para que ele desenvolva suas habilidades e competências para o cuidado, 0 que contribui para a construção da paternidade participativa. Nesse sentido, o pai necessita ser incluído no modelo de assistência as famílias. Embora os pais tenham a necessidade em estar presente e participar do cuidado, muitos sentem insegurança e não sabem como agir, porém podem contar com o enfermeiro como fonte de apoio no cuidado.

Os profissionais da saúde são importantes para auxiliar os homens a desenvolver novas habilidades e atitudes que facilitem a formação de vínculos entre pai e filho, oferecendo subsídios para que estes possam atuar no cuidado de seus filhos. Nesse sentido, para que o pai participe do processo de nascimento e cuidado de seus filhos, é fundamental sua inserção nos serviços de saúde com vistas a atendê-lo do pré-natal ao puerpério, contribuindo para minimização das inquietações e angústias que envolvem o homem no ciclo gravídico puerperal. ${ }^{15}$ A fala dos Enfermeiros indicou o desejo dos pais em participar de todos os momentos relacionados ao trabalho de parto e parto. No entanto, relataram que ainda há barreiras e limitações que impedem a participação do pai nesse momento.

Os Enfermeiros demonstraram conhecimento e a importância da política de humanização do parto, no que se refere à presença do pai no trabalho de parto, porém esse acesso ainda é limitado. De encontro aos resultados obtidos, autores destacam que compreender a experiência masculina do parto representa um marco na construção da assistência obstétrica. Assim, considera-se importante que os profissionais da saúde, possibilitem que o pai possa participar do nascimento do filho, oferecendo apoio emocional a sua companheira. ${ }^{16}$

Neste estudo, os Enfermeiros destacaram a resistência por parte dos profissionais médicos como um fator impeditivo para a participação do homem nesse momento que é tão importante para a família.

Alguns pais questionam o porque de não entrar, a gente sabe que existe bastante resistência por parte dos profissionais médicos. Mas com toda história da rede cegonha, humanização do parto, teria que ser uma determinação de cima para baixo, da direção [...] por que existe bastante resistência da parte médica. (E1)

Contudo, o direito de um acompanhante escolhido pela própria parturiente está garantido pela Lei $\mathrm{n}^{\circ}$ 11.108, de abril de 2005, que dispõe sobre o direito de um acompanhante durante todo o período de trabalho de parto, parto e pós-parto. ${ }^{17}$

Hoje em dia essa visão mudou bastante, quando eu comecei a trabalhar muito pouco se via os pais na maternidade, [...] hoje eu já vejo que os pais vem bastante, inclusive eles querem participar do momento do parto, muitos exigem esse direito, e eu vejo assim que os pais estão mais cuidadosos. (E1)

Além disso, a estrutura física do centro obstétrico e pediatria também foi apontada como um fator impeditivo da presença do pai no serviço de saúde. No centro obstétrico ao ter mais de uma gestante em trabalho de parto, a estrutura física torna-se 


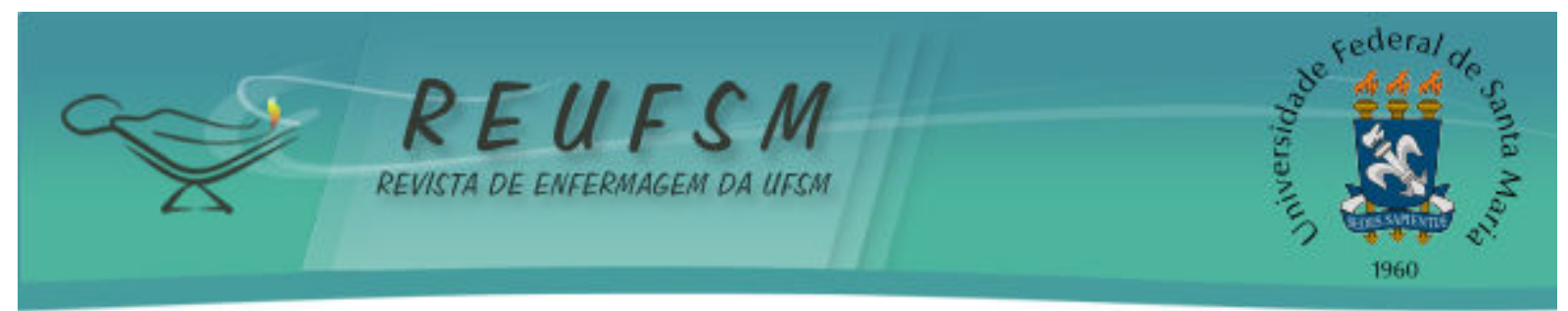

um limitador para a presença do homem, pois as mesmas ficam sem privacidade, expostas aos demais acompanhantes. Já na pediatria os enfermeiros percebem a importância do pai junto à criança no período de internação, porém reconhecem a estrutura física como impedimento para a concretização dessa presença devido à falta de espaço.

O que impede [a presença do homem] é a estrutura física, então teria que mudar alguma coisa na estrutura. Por isso que num primeiro momento não ficam. Quando tem só uma paciente aqui e esse familiar gostaria de vê-la ou ficar com ela, o que a gente costuma fazer, deixa ele entrar um pouco, aí ele sai um pouco. (E1)

Apesar do Estatuto da criança e do adolescente (ECA) determinar que o pai, também pode ser acompanhante da criança durante sua internação hospitalar, ${ }^{18}$ observa-se que a presença do pai ainda não é uma realidade devido à infraestrutura dos serviços de saúde.

Há algum tempo atrás não poderia ficar [na pediatria] ambos pais $e$ mães com a criança. Depois do Estatuto da criança, é permitido os dois, embora o hospital não tenha acomodação para os dois, mas é permitido que fique pai e mãe. A partir desse momento o pai se tornou mais presente, porque a mãe também fica insegura com a internação da criança e a presença do pai trás segurança para mãe e também divide o cuidado com a criança, nesse momento eu vejo mais isso aí talvez fortalecido. (E11)

Revisão integrativa realizada com objetivo de analisar a produção sobre a participação do pai enquanto acompanhante de seu filho hospitalizado, constatou que o envolvimento do pai nos cuidados de saúde com os filhos, durante a internação contribui para recuperação da criança. Contudo, os autores destacaram que durante o período em que os pais permanecem como acompanhante suas preocupações, angústias e medos são negligenciados. A Enfermagem necessita repensar o cuidado dispensado às famílias, refletindo sobre a inserção do pai na prestação de cuidados ao filho hospitalizado. ${ }^{19}$

\section{CONCLUSÕES}

O presente estudo identificou que, na visão dos Enfermeiros, o cuidado paterno na família contemporânea se dá por meio do compartilhamento das atividades de cuidado do filho. Destaca como fatores que influenciam a participação do homem no cuidado dos filhos, as interações que os profissionais de saúde estabelecem com o pai, as quais são determinantes para que ele desenvolva suas habilidades e competências para o cuidado do filho, embora a estrutura hospitalar constitua-se em impeditivo à participação.

Evidencia-se o distanciamento entre o preconizado pelas políticas públicas e literatura científica, com a realidade vivenciada nas instituições de saúde, pois mesmo havendo interesse dos pais em uma participação efetiva na família, não há estrutura adequada ou ações direcionadas que valorizem o potencial paterno. Nesta lacuna, observase a importância da Enfermagem em planejar e desenvolver ações que visem articular política/teoria com a prática, considerando características pessoais dos pais e possibilidades institucionais. 


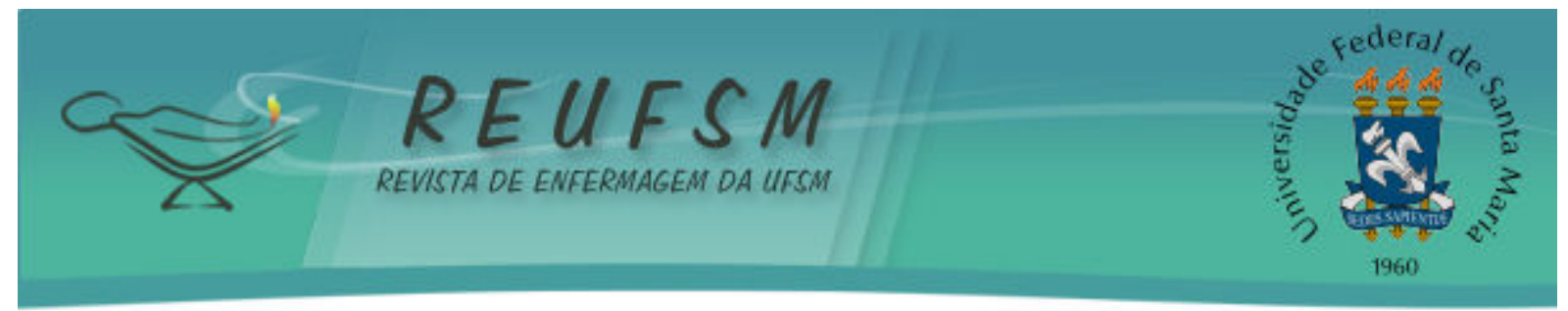

\section{REFERÊNCIAS}

1. Carvalho JBL, Brito RS, Araújo ACPF, Souza NL. Sentimentos vivenciados pelo pai diante do nascimento do filho. Rev RENE [Internet]. 2009 [acesso em 2014 abr 10];10(3):125-31. Disponível em: http://www.revistarene.ufc.br/vol10n3_pdf/a15v10n3.pdf.

2. Oliveira EMF, Brito RS. Ações de cuidado desempenhadas pelo pai no puerpério. Esc Anna Nery Rev Enferm [Internet]. 2009 [acesso em 2014 abr 10];13(3):595-601. Disponível em: http://www.scielo.br/pdf/ean/v13n3/v13n3a20.pdf.

3. Brasil. Ministério da Saúde. Secretaria de Atenção à Saúde, Departamento de Ações Programáticas e Estratégicas. Política Nacional de Atenção Integral à Saúde do Homem: princípios e diretrizes [Internet]. Brasília (DF): Ministério da Saúde; 2008 [acesso em 2014 abr 10]. Disponível em: http://bvsms.saude.gov.br/bvs/publicacoes/politica_nacional_atencao_homem.pdf.

4. Zampieri MFM, Guesser JC, Buendgens BB, Junckes JM, Rodrigues IG. O significado de ser pai na ótica de casais grávidos: limitações e facilidades. Rev Eletrônica Enferm [Internet]. 2012 [acesso em 2014 abr 10];14(3):483-93. Disponível em: http://www.fen.ufg.br/revista/v14/n3/pdf/v14n3a04.pdf.

5. Nogueira JRDF, Ferreira M. O envolvimento do pai na gravidez/parto e a ligação emocional com o bebê. Referência [Internet]. 2012 [acesso em 2014 ago 18];3(8):57-66. Disponível em: http://www.scielo.gpeari.mctes.pt/pdf/ref/vserllln8/serllIn8a06.pdf.

6 . Moraes R, Galiazzi MC. Análise textual discursiva. Ijuí: Editora Unijuí; 2011.

7. Perdomini FRI, Bonilha ALL. A participação do pai como acompanhante da mulher no parto. Texto \& Contexto Enferm [Internet]. 2011 [acesso em 2014 abr 10];20(3):444-52. Disponível em: http://www.scielo.br/pdf/tce/v20n3/04.pdf.

8. Cardinali F, Aires LCP, Monticelli M, Correia DS, Mendes L, Alcântara MG. O acompanhante no alojamento conjunto da maternidade. Rev Enferm UFSM [Internet]. 2011 jan/abr [acesso em 2014 maio 2];1(1):1-14. Disponível em: http://cascavel.ufsm.br/revistas/ojs-2.2.2/index.php/reufsm/article/view/2407/1506.

9. Luz AMH, Berni NIO. Processo de paternidade na adolescência. Rev Bras Enferm [Internet]. 2010 [acesso em 2014 ago 18];63(1):43-50. Disponível em: http://www.scielo.br/pdf/reben/v63n1/v63n1a08.pdf.

10. Galastro EP, Fonseca RMGS. A participação do homem na saúde reprodutiva: o que pensam os profissionais de saúde. Rev Esc Enferm USP [Internet]. 2007 [acesso em $2014 \mathrm{abr}$ 10];41(3):454-9. Disponível em: http://www.scielo.br/pdf/reeusp/v41n3/16.pdf.

11. Freitas WMF, Silva ATMC, Coelho EAC, Guedes RN, Lucena KDT, Costa APT. Paternidade: responsabilidade social do homem no papel de provedor. Rev Saúde Pública [Internet]. 2009 [acesso em 2014 ago 18];43(1):85-90. Disponível em: http://www.scielosp.org/pdf/rsp/v43n1/6868.pdf.

12. Massoudi P, Wickberg B, Hwang CP. Father's involvement in Swedish child health care the role of nurses practices and attitudes. Acta Pædiatrica [Internet]. 2011 [acesso em 2014 ago 18];100:396-01. Disponível em: http://www.ncbi.nlm.nih.gov/pubmed/21039828. 


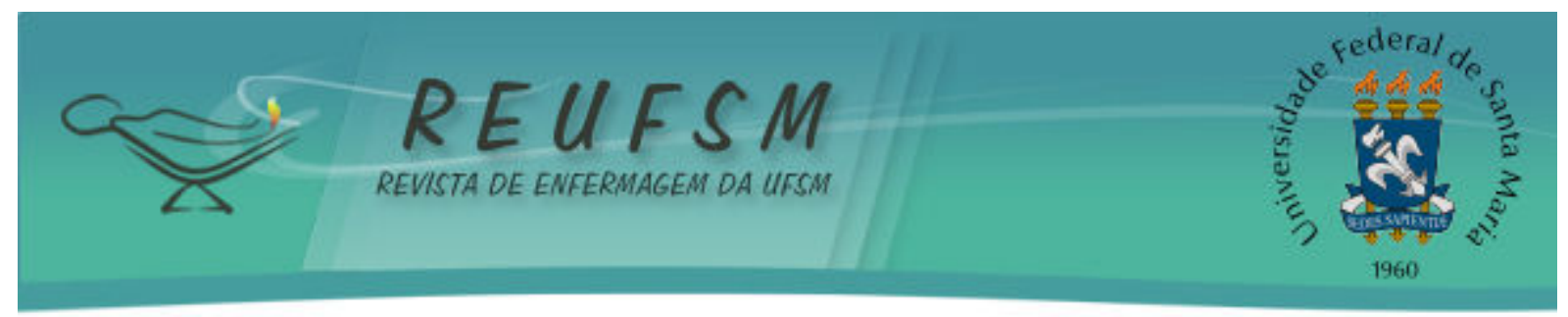

13. Oliva TA, Nascimento ER, Santo FRE. Percepções e experiências de homens relativas ao pré-natal e parto de suas parceiras. Rev Enferm UERJ [Internet]. 2010 [acesso em $2014 \mathrm{abr}$ 10];18(3):435-40. Disponível em: http://www.facenf.uerj.br/v18n3/v18n3a17.pdf.

14. Silva LJ, Silva LR. Mudanças na vida e no corpo: vivências diante da gravidez na perspectiva afetiva dos pais. Esc Anna Nery Rev Enferm [Internet]. 2009 [acesso em 2014 abr 10];13(2):393-401. http://www.scielo.br/pdf/ean/v13n2/v13n2a22.pdf.

Disponível

em:

15. Carvalho GM, Merighl MAB, Jesus MCP. Recorrência da parentalidade na adolescência na perspectiva dos sujeitos envolvidos. Texto \& Contexto Enferm [Internet]. 2009 [acesso em 2014 ago 18];18(1):17-24. Disponível em: http://www.scielo.br/pdf/tce/v18n1/v18n1a02.pdf.

16. Jardim DMB, Penna CMM. Pai-acompanhante e sua compreensão sobre o processo de nascimento do filho. Rev Min Enferm [Internet]. 2012 [acesso em 2014 ago 19];16(3):37381. Disponível em: http://www.reme.org.br/artigo/detalhes/540.

17. Brasil. Ministério da Saúde. Lei $n^{\circ} 11.108$, de 7 de abril de 2005. Altera a lei $n^{\circ} 8080$, de setembro de 1990, para garantir às parturientes o direito à presença de acompanhante durante o trabalho de parto, parto, e pós- parto imediato, no âmbito do Sistema único de Saúde - SUS [Internet]. Brasília (DF): Ministério da Saúde; 2005 [acesso em 2014 abr 10]. Disponível em: http://www.planalto.gov.br/ccivil_03/_Ato20042006/2005/Lei/L11108.htm.

18. Brasil. Ministério da Saúde. Estatuto da Criança e do Adolescente [Internet]. $3^{\mathrm{a}}$ ed. Brasília (DF); 2008 [acesso 2014 abr 10]. Disponível em: http://bvsms.saude.gov.br/bvs/publicacoes/estatuto_crianca_adolescente_3ed.pdf. (Série E. Legislação em Saúde).

19. Soares JD’AD, Brito RS de, Carvalho JBL de. A presença do pai/acompanhante no âmbito hospitalar: revisão integrativa. Rev Enferm UFPE Online [Internet]. 2014 [acesso em 2014 ago 18];8(7):2095-106. Disponível em: http://www.revista.ufpe.br/revistaenfermagem/index.php/revista/article/view/6022/pdf _5537.

Data de recebimento: $22 / 04 / 14$

Data de aceite: 05/11/2014

Contato com autor responsável: Bruna Silveira de Almeida

Endereço postal: Av.Itália,n² 2014 , Bairro Carreiros, Rio Grande/RS, Brasil. CEP: 96203-000.

E-mail: bruna_s_almeida@hotmail.com 